\title{
Substituted 2-(2-aminopyrimidin-4-yl) pyridine-4-carboxylates as potent inhibitors of JumonjiC domain-containing histone demethylases
}

\begin{abstract}
Background: Aberrant expression of iron(II)- and 2-oxoglutarate-dependent JumonjiC histone demethylases has been linked to cancer. Potent demethylase inhibitors are drug candidates and biochemical tools to elucidate the functional impact of demethylase inhibition. Methods \& results: Virtual screening identified a novel lead scaffold against JMJD2A with low-micromolar potency in vitro. Analogs were acquired from commercial sources respectively synthesized in feedback with biological testing. Optimized compounds were transformed into cell-permeable prodrugs. A cocrystal $x$-ray structure revealed the mode of binding of these compounds as competitive to 2-oxoglutarate and confirmed kinetic experiments. Selectivity studies revealed a preference for JMJD2A and JARID1A over JMJD3. Conclusion: Virtual screening and rational structural optimization led to a novel scaffold for highly potent and selective JMJD2A inhibitors.
\end{abstract}

Article submitted: 20 October 15; Article accepted: 14 December 2015;

Published online: 14 March 2016

Keywords: aminopyrimidylpyridines $\bullet$ epigenetics $\bullet$ histone demethylase $\bullet$ JumonjiC domain - metal chelators $\bullet$ prodrugs $\bullet$ virtual screening

Epigenetic mechanisms play a vital role in gene expression regulation both in healthy as well as disease cells. Dynamic regulational control is maintained by a network of chemical modifications both to DNA as well as to the proteins, around which it is wrapped, the histones. These include methylation on cytosines within the DNA and on lysine and arginine residues in histone tails, acetylation on lysines, phosphorylation on serines and threonines, ubiquitination and others [1-4]. This is mediated by a complex system of writer enzymes (e.g., acetyl- and methyltransferases), eraser enzymes (e.g., deacetylases, demethylases) as well as reader proteins (containing e.g., bromodomains, chromodomains), which can recognize these modifications and recruit further effector proteins $[1,4,5]$. Histone lysine methylation can have both repressive as well as activating functions depending on the context $[6,7]$. In order to study the role of theses enzymes and readers, the need for potent and selective small-molecule inhibitors as chemical tool compounds as well as therapeutic candidates has been recognized $[5,8,9]$.

While histone lysine methylation was long believed to be a permanent modification [10], this view was revised when the first lysinespecific demethylase 1 was discovered in 2004 [11]. For mechanistic reasons, this FADdependent monoamine oxidase-like enzyme can only demethylate mono- and di-methylated lysine residues [11,12]. Two years later, the much larger class of JumonjiC (JmjC) domain-containing histone demethylases was discovered [13,14], comprising around 30 family members that have been identified to date and can be categorized into seven subfamilies $[15,16]$.

These metalloenzymes belong to the cupin superfamily and demethylate lysine residues
Martin Roatsch', Dina Robaa², Martin Pippel2, Joanne E Nettleship ${ }^{3}$, Yamini Reddivari ${ }^{3}$, Louise E Bird ${ }^{3}$, Inga Hoffmann', Henriette Franz ${ }^{4}$,

Raymond J Owens ${ }^{3}$, Roland Schüle ${ }^{4}$, Ralf Flaig ${ }^{5}$, Wolfgang Sippl ${ }^{2}$

\& Manfred Jung *,1

${ }^{1}$ Albert-Ludwigs-University Freiburg, Institute of Pharmaceutical Sciences, Albertstraße 25, 79104 Freiburg i.Br. Germany

${ }^{2}$ Martin-Luther-University HalleWittenberg, Institute of Pharmacy, Wolfgang-Langenbeck-Straße 4, 06120 Halle (Saale), Germany ${ }^{3}$ Oxford Protein Production Facility UK (OPPF-UK), Rutherford Appleton Laboratory, Harwell Science \& Innovation Campus, Didcot, Oxfordshire, OX11 OFA, UK

${ }^{4}$ University Medical Center Freiburg, Central Clinical Research, Breisacher Straße 66, 79106 Freiburg i.Br., Germany ${ }^{5}$ Diamond Light Source, Harwell Science \& Innovation Campus, Didcot, Oxfordshire, OX11 ODE, UK

*Author for correspondence:

Tel.: +497612034896

Fax: +497612036321

manfred.jung@pharmazie.uni-freiburg.de 
of all methylation states in an iron(II)- and 2-oxoglutarate-dependent manner. In a radical mechanism, the methyl group is oxidized to a hydroxymethyl moiety, which, due to its unstable hemiaminal nature, spontaneously decomposes to yield formaldehyde and the demethylated lysine residue. The cosubstrate 2-oxoglutarate $\mathbf{1 a}$ is cleaved to carbon dioxide and succinate [1416]. All family members have their unique selectivity profile as to which lysine residue in the histone sequence is accepted as well as the degree of methylation $[16,17]$.

JmjC domain-containing histone demethylases have been implicated in the initiation and manifestation of several diseases, in particular in the context of oncology [2,3,5,9,16-21]. The demethylase subtype JMJD2A (KDM4A), a member of the JMJD2 (KDM4) subfamily (members A-E), which is specific for di- and trimethylated lysine residues 9 and 36 on histone $\mathrm{H} 3$ $\left(\mathrm{H} 3 \mathrm{~K} 9 / 36 \mathrm{me}_{2 / 3}\right)[16,22]$, has also been shown to be vital to the proliferation of a certain number of tumor cell lines, in particular hormone-dependent tumors such as prostate [23] and breast cancer [24,25] by coactivation of the androgen and estrogen receptor, respectively. Elevated levels of JMJD2A in other tumor types have also been reported such as in colorectal [26], lung [27] and bladder [28] cancer. However, there are also contrasting reports, which suggest reduced levels of JMJD2A in malignantly transformed urothelium as compared with healthy tissue and propose reduced levels as a marker for poor prognosis [29]. The complex role of JMJD2A in cancer tissues has recently been summarized by GuerraCalderas et al. [21]. Nevertheless, there is an interest in the development of potent inhibitors of JMJD2A and other JmjC histone demethylases either as candidates for anticancer therapy or to study their biological roles $[9,17]$.

A number of inhibitors for JmjC histone demethylases have been published to date, of which a selection is summarized in Figure 1. Advances in inhibitor design have recently been reviewed [17,30-34]. Among the first published inhibitors were metal ion chelators, which bind to the ferrous ion center and competitively displace the cosubstrate 2-oxoglutarate 1a, such as $\mathrm{N}$-oxalylglycine $\mathbf{1} \mathbf{b}$ with proven potency against the closely related subtype JMJD2E [35]. $1 \mathbf{b}$ is an amide analog of $\mathbf{1 a}$ and was recently also shown to occur as a natural product in rhubarb leaves [36]. Among the panel of the first JMJD2E inhibitor scaffolds, 2,4-pyridinedicarboxylic acid (2,4-PDCA, 2) [35], now a standard reference inhibitor for in vitro applications, was also reported along with hydroxamic acids such as trichostatin A and its simplified version SAHA 3 [35]. Compound 3 has been optimized into structures like 4 as inhibitors of JMJD2A and JMJD2C [37]. Among the metal ion chelators, the 2,2'-bipyridyl moiety is a privileged structure as demonstrated by lead compound 5a [35] and its optimized derivative 5b [38], both inhibitors of JMJD2E. Similarly, the 8-hydroxyquinoline scaffold has been demonstrated to generate potent inhibitors of JMJD2E like IOX1 6 in a first high-throughput screening campaign [39]. By coupling the bipyridyl lead scaffold $\mathbf{5}$ and the hydroxyquinoline scaffold $\mathbf{6}$ to the lysine-specific demethylase 1 inhibitor tranylcypromine, dual inhibitors of both classes of demethylases could be obtained [40]. Recently, the lead compound GSK-J1 7 was published with a remarkable in vitro potency of $60 \mathrm{nM}$ and a striking selectivity for the KDM6 subfamily over representatives from the KDM3 and KDM4 subfamilies as well as other demethylases [41]. Shortly after, however, the selectivity of 7 was called into question as it was found to also inhibit demethylases of the KDM5 subfamily with relatively high potency $[42,43]$. Nonetheless, it stands to be one of the most potent and selective inhibitors published to date. Furthermore, we have recently discovered the fragment-like tetrazolylhydrazide $\mathbf{8}$ to be a potent inhibitor of KDM4A with remarkable selectivity over two other demethylases. It is a cosubstrate 2-oxoglutarate mimic using a tetrazole moiety as a bioisosteric replacement of a carboxylic acid [44].

Generally, most published inhibitors suffer from lack of selectivity among ferrous ion-containing enzymes or their selectivity has not been investigated. Furthermore, as these metal ion chelators are generally quite polar molecules, investigation of their biological effects is often hindered by their limited cell permeability [8].

Here, we describe the identification of novel highly potent inhibitors of JMJD2A, which were identified by virtual screening and optimized yielding an inhibitor with a $K_{\mathrm{i}}$ value of only $186 \mathrm{nM}$. A synthetic platform for the generation of more analogs with effects on cell proliferation of an esophageal carcinoma cell line was established. X-ray crystallography reveals binding of these inhibitors in the enzyme active site in a cosubstrate competitive manner. The selectivity of our inhibitors against a panel of three demethylases was evaluated.

\section{Materials \& methods}

\section{Virtual screening campaign}

Filtering database for metal-binding motifs

Metal binding motifs were extracted from nine available JMJD2A crystal structures (PDB IDs 4ai9, 4gd4, 2gp5, 2oq6, 2vd7, 2wwj, 2ybs, 3u4s and 3pdq) and converted into a substructure search query. For this purpose, the in-house developed docking software tool ParaDockS [45] was used. ParaDockS provides a substructure search with an own definition language called PSSD (ParaDockS Substructure Search 
<smiles>O=C(O)CC(=O)C(=O)O</smiles>

1a $\mathrm{X}=\mathrm{CH}_{2}$ 1b $X=N H$

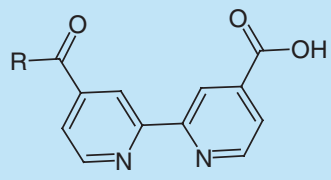

5 a $\mathrm{R}=\mathrm{OCH}_{3}$ 5b $\mathrm{R}=\mathrm{NHCH}_{2} \mathrm{CH}_{2} \mathrm{NH}_{2}$<smiles>O=C(O)c1ccnc(C(=O)O)c1</smiles><smiles>O=C(O)c1ccc(O)c2ncccc12</smiles><smiles>O=C(CCCC(=O)Nc1ccccc1)NO</smiles>

3

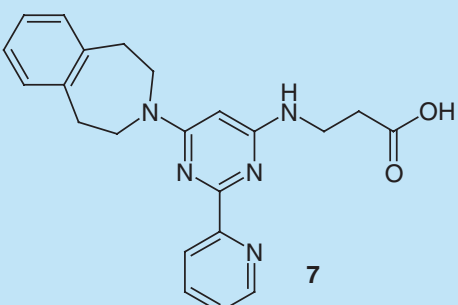<smiles>CN(C)CC(=O)N(O)CCC(=O)O</smiles>

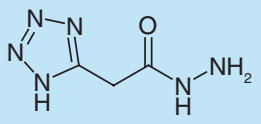

8

Figure 1. Chemical structure of the enzyme's cosubstrate 2-oxoglutarate 1a and summary of previously reported JumonjiC demethylase inhibitors $(1 b-8)$.

Description). The ZINC clean drug-like database (version 2013) was screened for PSSD metal binding patterns (cf. Figure 2A), resulting in 528,932 unique compounds. Since we planned to use regional constraints in the subsequently described docking setup, the atom numbers of the metal binding motif were reassigned (1-4 for metal binding motif) using ParaDockS.

\section{Docking of virtual screening hits Protein preparation}

The nine PDB structures of JMJD2A (see above) were retrieved from the Protein Data Bank. Only chain A of each PDB structure was kept and the water molecules were removed. The protonated form of all protein structures was generated at the physiological $\mathrm{pH}$ using the protonate3D procedure implemented in the Molecular Operating Environment (MOE) modeling package version 2012.10 (Chemical Computing Group, Montréal, Canada). The protein structures were subsequently energy-minimized in $\mathrm{MOE}$ by applying Amber99 force field and the GB/SA solvent model using a tethering constant of up to $100 \mathrm{kcal} /(\mathrm{mol} \cdot \AA)$. The structures were finally superposed in MOE.

\section{Ligand preparation}

All ligands were prepared using MOE software. Their protonated form was generated at the physiological $\mathrm{pH}$ using the Wash procedure and a subsequent energy minimization was carried out using MMFF94x force field as implemented in MOE.

\section{Docking setup}

The ligands were docked into an ensemble of the nine prepared protein structures using GOLD docking program version 5.0.1 [46]. The binding pocket was assigned by $14 \AA$ around the center of the binding pocket and PLP-score was chosen as the fitness function. A maximum of 10 GA runs for each compound was allowed. Meanwhile, the search efficiency was set at $75 \%$ and early termination was enabled to allow a quicker screening. Regional constraints were implemented for the preassigned atoms corresponding to the metal-binding motif in each structure to restrain them in the vicinity of the metal ion. Here, a sphere of $3 \AA$ around the metal ion was set as the region where the atoms of the metal-binding motif should be positioned.

\section{Docking studies and substructure search for (pyrimidin-4-yl) pyridine derivatives \\ Docking studies}

Compounds 9a and $\mathbf{9 b}$ (cf. Table 1) as well as the hits from the subsequently described substructure search were docked into chain A of the PDB structure 3pdq, while keeping four water molecules in the binding pocket (HOH470, 524, 539 and 643). The protein structure and the ligands were prepared in MOE as previously described. Docking was performed using GOLD [46], where Goldscore was chosen as the fitness function, and no constraints were applied. This procedure was successful in reproducing the right binding mode for the bipyridyl derivative $\mathbf{5 b}$, cocrystallized in 3 pdq.

\section{Substructure search}

The filter module as implemented in OEChem software version 1.7.4 (OpenEye Scientific Software, Santa Fe, NM, USA) was applied for searching the SMARTS pattern $\mathrm{OC}(=\mathrm{O}) \mathrm{clcc}(\mathrm{ncc} 1)$-clnc(ncc1)N for the 2-(2-aminopyrimidin-4-yl)pyridine-4-carboxylate moiety in the ZINC drug-like database (zinc.docking website). The purchasability of the retrieved compounds was checked 
(A)
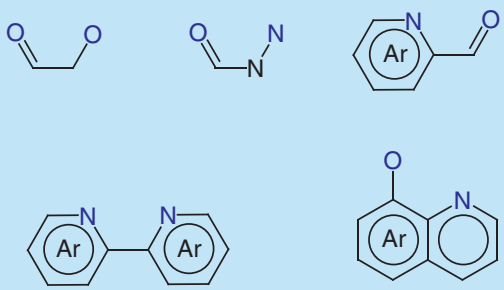

(C)

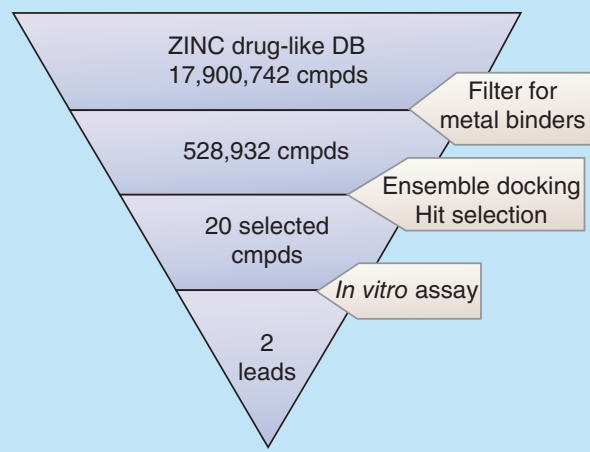

C)
(B)

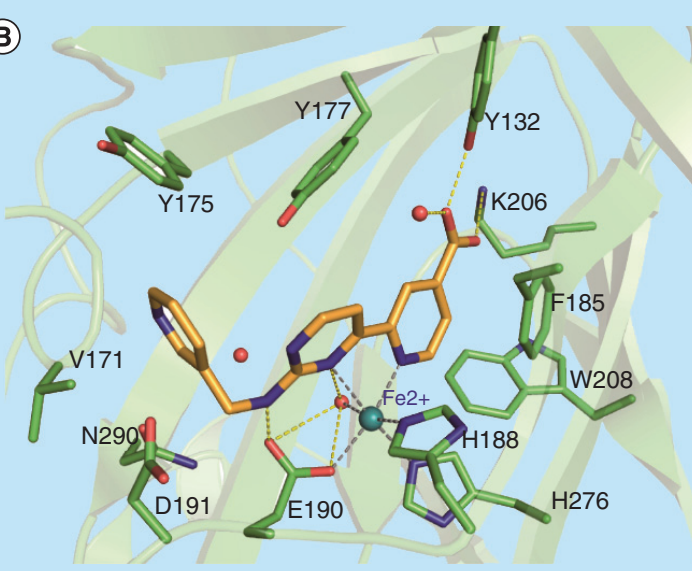

Figure 2. Virtual screening campaign towards novel JmjC inhibitors. (A) Metal-binding motifs selected for filtering the ZINC drug-like database. Ar stands for any N-containing aromatic ring. The metal-coordinating atoms are colored in blue. (B) Docking pose of 9a (orange) in JMJD2A (green, PDB code: 3pdq). Only the side chains of the protein residues involved in the interaction are shown. Water molecules are shown as red spheres, the ferrous ion as cyan sphere, $\mathrm{H}$-bond and salt bridge interactions as yellow dashed lines and the metal coordination as gray dashed lines. (C) Virtual screening workflow.

on the ZINC website, and only purchasable compounds were considered for the subsequent docking step.

\section{Screening compounds}

Screening compounds of the general lead structure 9 were obtained from ChemBridge (CA, USA, hit2lead. com) or synthesized in-house as specified. Control compounds $\mathbf{1 0}$ and $\mathbf{1 1}$ were from Enamine (Kiev, Ukraine). Mocetinostat 12 was obtained via Selleckchem (TX, USA). Reference inhibitor 2,4-PDCA 2 was obtained from Acros Organics (Geel, Belgium) and GSK-J1 7 and control compound $\mathbf{1 3}$ were from Sigma-Aldrich (MO, USA). Commercial compounds were tested as supplied without further analysis or purification.

\section{Expression \& purification of JMJD2A (KDM4A) for in vitro assays}

The plasmid pNIC28-Bsa4 JMJD2A encoding human KDM4A residues 1-359 were used for expression and purification as described by $\mathrm{Ng}$ et al. with minor modifications [22]. Shortly, the expression construct was transformed in BL21-CodonPlus-Ril competent cells. Six liters of TB media containing kanamycin $\left(50 \mu \mathrm{g} \cdot \mathrm{ml}^{-1}\right)$ and chloramphenicol $\left(34 \mu \mathrm{g} \cdot \mathrm{ml}^{-1}\right)$ were inoculated with a $15 \mathrm{ml} \cdot \mathrm{l}^{-1}$ overnight culture and grown at $37^{\circ} \mathrm{C}$. Expression was induced by addition of $0.2 \mathrm{mM} \mathrm{IPTG}$ at $A_{260}=0.6$. Then, the culture was incubated at $18^{\circ} \mathrm{C}$ for another $18 \mathrm{~h}$. After harvesting and lysis of the bacteria, the protein was purified by a Talon bead column. The purity of KDM4A estimated by SDS-PAGE was above $90 \%$.

\section{JMJD2A (KDM4A) LANCE assay}

The commercial antibody-based LANCEUltra demethylase activity assay (PerkinElmer, MA, USA) was performed in a total volume of $10 \mu \mathrm{l}$ on white OptiPlate-384 microtiter plates (PerkinElmer) using a $50 \mathrm{mM}$ HEPES buffer at $\mathrm{pH}=7.50$ containing $0.01 \%$ Tween-20 and $0.01 \%$ BSA. A solution of 60 
Table 1. IC $C_{50}$ values of all tested inhibitor compounds of the general lead structure 9 in the in vitro LANCE assay against JMJD2A (KDM4A).
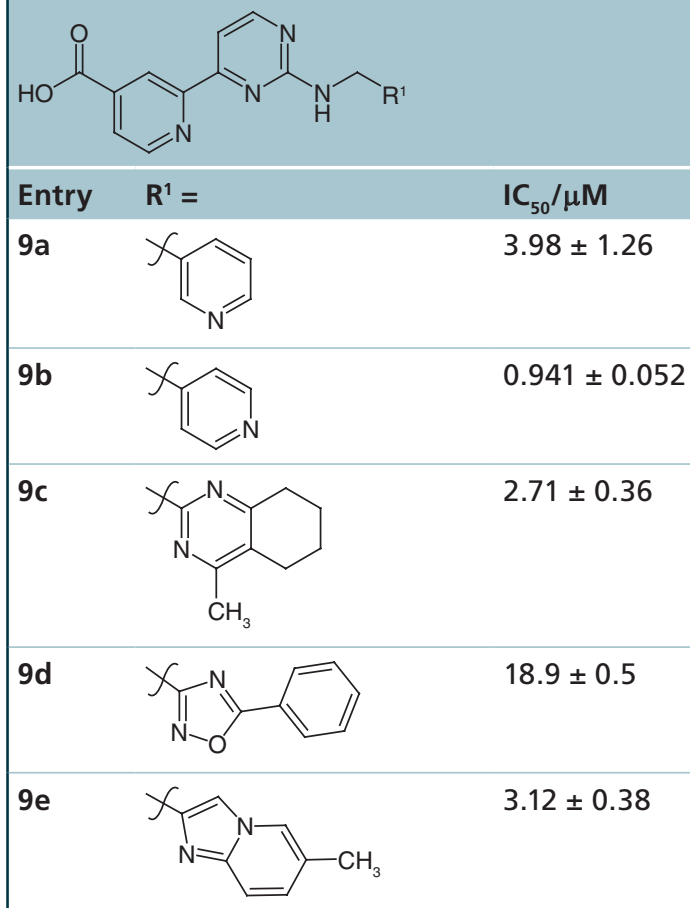

96

$3.92 \pm 0.09$

$9 g$

$8.07 \pm 0.80$

$9 \mathrm{~h}$<smiles>Cc1cn2c(n1)SCC2</smiles>

$3.89 \pm 0.97$

$9 i$<smiles>Cc1nnc2ccccn12</smiles>

$5.10 \pm 1.10$

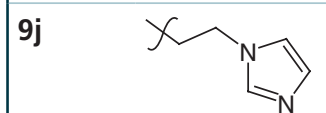

$1.83 \pm 0.37$

$9 k$<smiles>CCNC(=O)c1ccncc1</smiles>

$7.16 \pm 0.89$

9l

$X=N$

$1.40 \pm 0.22$

$I_{50}$ values are reported as mean \pm SD of at least two independent experiments.
Table 1. $I C_{50}$ values of all tested inhibitor compounds of the general lead structure 9 in the in vitro LANCE assay against JMJD2A (KDM4A) (cont.).
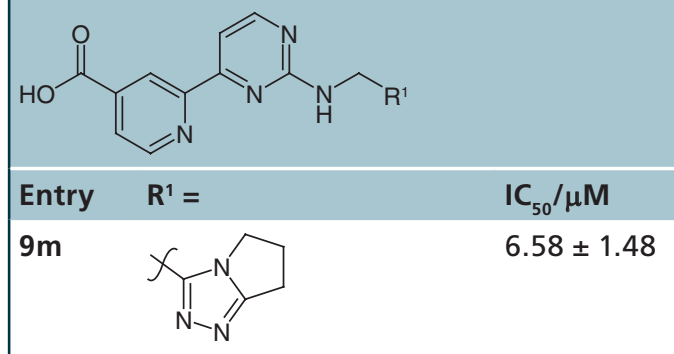

9 n

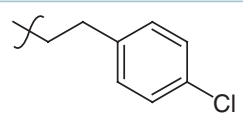

$4.76 \pm 2.33$

90

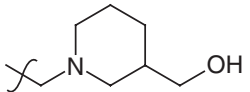

$9 p$ NOH<smiles>CCc1nc2c(s1)CCC2</smiles>

$3.27 \pm 0.04$

$$
x=N
$$

99

$28.5 \pm 4.2$

9r

$9 u$

$1.57 \pm 0.09$

$9 v$

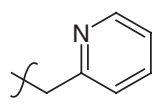

$7.42 \pm 1.84$

$9 w$

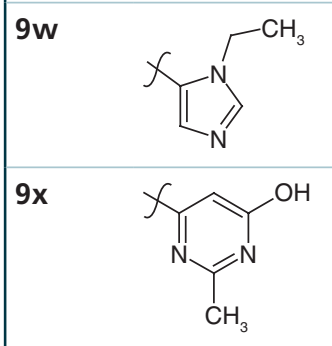

$1.95 \pm 0.11$

$I C_{50}$ values are reported as mean \pm SD of at least two independent experiments. 
Table 1. $I C_{50}$ values of all tested inhibitor compounds of the general lead structure 9 in the in vitro LANCE assay against JMJD2A (KDM4A).

9ab

nM JMJD2A (KDM4A) 1-359 was preincubated with compound solutions of varying concentration in DMSO at room temperature for $10 \mathrm{~min}$. A substrate solution containing $100 \mu \mathrm{M}$ ascorbic acid, $5 \mu \mathrm{M} \mathrm{FeSO}_{4}, 1 \mu \mathrm{M}$ 2-oxoglutarate and 400 $\mathrm{nM}$ of biotinylated $\mathrm{H} 3 \mathrm{~K} 9 \mathrm{me}_{3}$ 1-21 substrate peptide ARTKQTARK $\left(\mathrm{me}_{3}\right)$-STGGKAPRKQLA-
Table 1. IC $C_{50}$ values of all tested inhibitor compounds of the general lead structure 9 in the in vitro LANCE assay against JMJD2A (KDM4A).
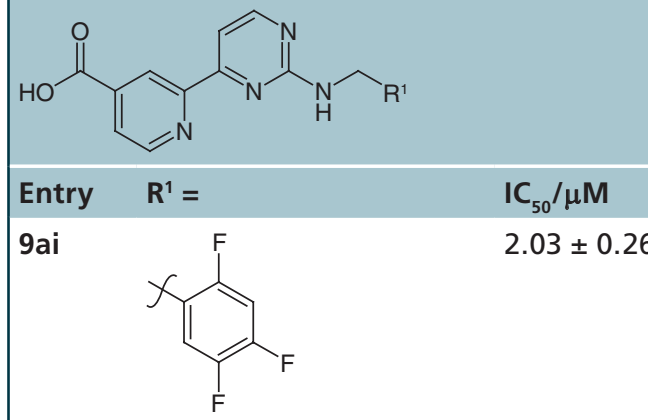

9aj

9al

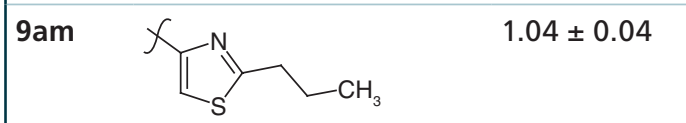

$1.30 \pm 0.28$

GGK(biotin) (BPS Bioscience, CA, USA) was added (final concentrations). Final DMSO concentration was $5 \%$ in all wells. Plates were incubated on a horizontal shaker at room temperature for $45 \mathrm{~min}$. Reactions were stopped by addition of $10 \mu \mathrm{l}$ of detection mix containing $2 \mathrm{nM}$ europium-labeled anti$\mathrm{H} 3 \mathrm{~K} 9 \mathrm{me}_{2}$ LANCE antibody (PerkinElmer), $50 \mathrm{nM}$ 
ULight-streptavidin dye (PerkinElmer) and $1 \mathrm{mM}$ EDTA in 1X LANCE detection buffer (PerkinElmer) (final concentrations). Plates were again incubated on a horizontal shaker at room temperature for $60 \mathrm{~min}$. FRET intensity was measured on a PerkinElmer EnVision 2102 multilabel plate reader at $\lambda_{\text {ex }}$ $=340 \mathrm{~nm}$ and $\lambda_{\text {em }}=665 \mathrm{~nm}$ with a delay of $100 \mu \mathrm{s}$. Values were blank-corrected and activity in $\%$ is in comparison to compound-free DMSO control and no-enzyme negative control. Inhibition curves were analyzed by sigmoidal curve fitting using GraphPad Prism 4.00 (GraphPad Software, CA, USA) and $\mathrm{IC}_{50}$ values calculated from the fit parameters as mean \pm $\mathrm{SD}$ from two independent experiments.

\section{JARID1A (KDM5A) LANCE assay}

The antibody-based LANCEUltra activity assay for JARID1A (KDM5A) was performed essentially as described for JMJD2A (KDM4A) with the following modifications: a solution of $25 \mathrm{nM}$ full-length JARID1A 1-1090 (BPS BioScience, CA, USA) was used with $100 \mathrm{nM}$ of biotinylated $\mathrm{H}_{3} \mathrm{~K}_{4} \mathrm{me}_{3}$ 1-21 substrate peptide ARTK $\left(\mathrm{me}_{3}\right)$-QTARKSTGGKAPRKQLA-GGK(biotin) (AnaSpec, CA, USA). The detection mix contained the appropriate europium-labeled anti-H3K4me $/ \mathrm{me}_{1}$ LANCE antibody (PerkinElmer).

\section{JMJD3 (KDM6B) LANCE assay}

The antibody-based LANCEUltra activity assay for JMJD3 (KDM6B) was performed essentially as described for JMJD2A (KDM4A) with the following modifications: a solution of $50 \mathrm{nM}$ catalytic domain JMJD3 1043-end (BPS BioScience, CA, USA) was used with $400 \mathrm{nM}$ of biotinylated H3K27me ${ }_{3} 21-44$ substrate peptide ATKAARK $\left(\mathrm{me}_{3}\right)$-SAPATGGVKKPHRYRPG-GK(biotin) (PSL Peptide Specialty Laboratories, Heidelberg, Germany). Incubation time for the enzymatic reaction was $120 \mathrm{~min}$ and the detection mix contained the appropriate europium-labeled anti$\mathrm{H} 3 \mathrm{~K} 27 \mathrm{me}_{2}$ LANCE antibody (PerkinElmer).

\section{JMJD2A (KDM4A) 2-oxoglutarate competitivity assay}

In order to assess the competitivity of enzyme inhibition by test compounds to 2-oxoglutarate, the LANCEUltra assay was performed as described above with varying concentrations of 2-oxoglutarate $(0 \ldots 5.0 \mu \mathrm{M})$ and inhibitor. Each combination was tested in duplicate. The blank-corrected LANCE signal was compared with a pre-established calibration curve to determine the amount of demethylated product formed and, thus, the reaction velocity over the incubation time. Curve fitting was performed using the Michaelis-Menten equation:

$$
V=\frac{V_{\max } \cdot[2 \text {-oxoglutarate }]}{K_{\mathrm{M}}+[2 \text {-oxoglutarate }]} \text {. }
$$

The apparent $K_{\mathrm{M}}$ values were plotted against the concentration of inhibitor to obtain $K_{\mathrm{i}}$ by linear regression to the equation:

$$
K_{\mathrm{M}}^{\mathrm{app}}=K_{\mathrm{M}}^{0}\left(1+\frac{[\text { compound }]}{K_{\mathrm{i}}}\right) .
$$

\section{Synthesis}

Full experimental details for the synthesis of inhibitors and their prodrugs along with their characterization data can be found in the Supplementary Information.

\section{Physicochemical properties}

Computational $\log \mathrm{P}$ values were calculated using the built-in $\log \mathrm{P}$ tool of ChemSketch (Freeware) 2012 14.01 (ACD/Labs, Toronto, Canada).

\section{KYSE-150 cell proliferation experiments}

KYSE-150 cells [47] were obtained from the Leibniz Institute DSMZ-German Collection of Microorganisms and Cell Cultures and cultivated using a mixture of 49\% RPMI 1640, 49\% Ham's F12 and 2\% FCS supplemented with $2 \mathrm{mM}$ L-glutamine in a $5 \% \mathrm{CO}_{2}$ atmosphere at $37^{\circ} \mathrm{C}$. For the proliferation assay, cells were seeded in 96-well plates at a density of 5000 cells per well. Compounds were dissolved in DMSO and added to cells the next day with the final concentration of DMSO in media being $0.5 \%$. Pure solvent was used as a control. A minimum of five wells was used for each condition. After an incubation time of $72 \mathrm{~h}$, the CellTiter $96^{\circledR}$ AQueous Non-Radioactive Cell Proliferation Assay from Promega was performed according to the manufacturer's instructions and plates were measured on a POLARstar Optima microplate reader (BMG Labtech, Ortenberg, Germany). All values were averaged and blank-subtracted. The DMSO control was normalized to $100 \%$ and other values calculated accordingly. Growth inhibition data were confirmed in an independent experiment. An unpaired, one-tailed t-test was performed as indicated using GraphPad Prism 4.00 (GraphPad Software) to evaluate the significance of the observed changes in cell proliferation.

\section{Expression \& purification of JMJD2A (KDM4A) for X-ray crystallography}

The coding sequence for hJMJD2A (1-359) was cloned into pOPINF using the InFusion method described previously [48,49]. The protein was produced in Esch- 
erichia coli strain Rosetta pLysS (DE3) using the autoinduction method [50]. The cells were harvested by centrifugation and frozen at $193 \mathrm{~K}$. The purification protocol followed that described previously [51]. Briefly, defrosted cells were lysed and the soluble fraction was purified via nickel-chelation chromatography followed by gel filtration chromatography. Protein-containing fractions were pooled and the purified protein was concentrated to $13 \mathrm{mg} \cdot \mathrm{ml}^{-1}$ in $20 \mathrm{mM}$ Tris buffer at $\mathrm{pH} 7.5$ containing $200 \mathrm{mM} \mathrm{NaCl}$ prior to crystallization. The yield of pure protein was $11 \mathrm{mg}$ of protein per liter of E. coli culture.

Crystallization screening was carried out as published elsewhere [52] and several conditions were identified, with crystals appearing approximately after 2 weeks of incubation at $294 \mathrm{~K}$. Initial crystallization conditions were tested using in situ screening at beamline I04-1 at Diamond Light Source [53]. Based on these results, grid screens around the most promising conditions (Hampton Index conditions F7, F8, G2, G4) were set up to optimize crystallization.

\section{X-ray crystallography}

The JMJD2A-5yq (9a) complex was formed by mixing JMJD2A (13 $\left.\mathrm{mg} \cdot \mathrm{ml}^{-1}\right)$ with a fivefold molar excess of 5 yq $(9 \mathbf{a})$ ligand. Crystals (space group $P 22_{1} 2$ ) were grown by sitting drop vapor diffusion at $277 \mathrm{~K}$ in buffer containing $100 \mathrm{mM}$ HEPES at $\mathrm{pH} 7.5,0.233 \mathrm{M}$ $\mathrm{Li}_{2} \mathrm{SO}_{4}$ and $24 \%$ (w/v) PEG-3350. Prior to flash cooling in liquid nitrogen, crystals were cryoprotected in reservoir solution with $10 \%(\mathrm{v} / \mathrm{v})$ glycerol. The data set for the final refined model was collected at $100 \mathrm{~K}$ at beamline I04 at Diamond Light Source. Data were processed and analyzed with XDS [54] and Aimless [55]. The structure was solved by molecular replacement with MOLREP [56] using PDB 2ox0 as search model with the cofactors and solvent molecules removed. The CIF file for the ligand restraints was generated with ace$\mathrm{drg}$ from the CCP4 program suite [57]. Manual building and refinement were performed using Coot [58] and Refmac5 [59] in the CCP4 program suite [57] and Buster 2.11.5 (Global Phasing, Cambridge, UK). The final model was validated by MolProbity [60] and the RCSB Validation Server. Supplementary Table 2 summarizes the statistics for data collection and refinement. Structural figures were generated in PyMOL 1.7.4 (Schrödinger, NY, USA). The coordinates and structure factors have been deposited in the Protein Data Bank with accession code 5anq.

\section{Results \& discussion}

Virtual screening generates novel lead scaffold In order to generate novel potent JMJD2A inhibitors, we employed a structure-based virtual screen- ing approach. For this purpose, the ZINC drug-like database was filtered for compounds containing a metal-binding motif, similar to those found in known JmjC inhibitors. An overview of the selected structural motifs is shown in Figure 2A. The obtained compounds (ca. 530,000) were docked into an ensemble of JMJD2A crystal structures, using regional constraints for the metal-binding moiety to restrain it in a position where metal coordination is possible. This docking setting was able to reproduce the binding mode of all cocrystallized ligands in a preliminary cross-docking procedure.

A total of 20 compounds were selected (cf. Supplementary Figure 1) based on their purchasability, docking scores, interaction pattern within the binding pocket of the enzyme and structural diversity and tested for their in vitro activity against JMJD2A in the commercial antibody-based LANCEUltra assay.

In this assay system, a biotinylated substrate peptide of the original histone $\mathrm{H} 3$ sequence containing trimethyllysine as an unnatural amino acid at position 9 is incubated with the catalytic domain of JMJD2A and iron(II), ascorbic acid and 2-oxoglutarate. After incubation, a europium-labeled highly specific antibody is added, which binds the product $\mathrm{H} 3 \mathrm{~K} 9 \mathrm{me}_{2}$, but not $\mathrm{H} 3 \mathrm{~K} 9 \mathrm{me}_{3}$, along with a streptavidin-bound proprietary dye ULight. If both the dye and the antibody bind to the peptide, a FRET effect can be measured. In case a test compound inhibited demethylation, the antibody would not bind to the peptide and no FRET could be observed.

Among all tested compounds (cf. Supplementary Figure 1), only the 2-(pyrimidin-4-yl) pyridine derivatives $(\mathbf{9 a}$ and $\mathbf{9 b}$, cf. Table 1) from the ChemBridge hit2lead.com screening library showed a promising inhibitory activity with $\mathrm{IC}_{50}$ values in the single-digit micromolar range. A striking fourfold difference in potency between $\mathbf{9 a}$ and $\mathbf{9 b}$ was observed, although these compounds only differ in the substitution pattern at the pyridine substituent. This difference was confirmed with new batches of both compounds.

To assess the binding mode of both hit compounds 9a and 9b, docking studies were performed using the crystal structure of JMJD2A in complex with the bipyridyl JmjC inhibitor 5b (PDB code: 3pdq), since it represents the structurally closest analog of these compounds. As seen in the suggested binding mode of $9 \mathbf{a}$ in JMJD2A (Figure 2B), the pyridyl- and pyrimidyl-N chelate the ferrous ion, while the carboxylate group undergoes salt bridge interactions with Lys206 and H-bond interactions with Tyr132 and a water molecule. An additional $\mathrm{H}$-bond interaction is formed between the secondary NH-group and Glu190. The (pyridin-3-yl)methyl substituent at the $\mathrm{NH}$-group is 
embedded in a pocket formed by Val171, Tyr175 and Tyr177, without forming any additional interactions with the residues in the binding pocket.

In vitro testing \& structure-activity relationship To further explore (pyrimidin-4-yl)pyridine derivatives as JMJD2A inhibitors, a second substructure search was conducted in the ZINC drug-like database to select all compounds bearing a 2-(2-aminopyrimidin-4-yl)pyridine-4-carboxylic acid moiety. The retrieved 381 purchasable compounds were subsequently docked like previously described for $\mathbf{9 a}$ and $\mathbf{9 b}$, and an initial subset of 18 compounds was selected according to their docking score, interaction pattern and the structural diversity of the substituent at the amino group (cf. Figure $2 \mathrm{C}$ for the virtual screening selection process).

Consequently, this collection of compounds was acquired and tested in vitro $(\mathbf{9 a}-\mathbf{r})$. Most compounds showed potent inhibition of demethylation by JMJD2A with $\mathrm{IC}_{50}$ values between 0.9 and $8.1 \mu \mathrm{M}$ (cf. Table 1). Remarkably potent derivatives were those with a small basic aromatic substituent like $\mathbf{9 b}$ (pyridine, $0.9 \mu \mathrm{M}$ ), 9j ( $N$-imidazolylethyl, $1.8 \mu \mathrm{M}$ ) and $9 \mathbf{1}$ (imidazole, 1.4 $\mu \mathrm{M}$ ), indicating that they might be involved in additional interactions farther away from the metal center. These residues protrude into an adjacent water-filled subpocket, where they might function as hydrogen bond acceptors if oriented appropriately. However, these additional interactions could not be observed in the docking poses.

Out of this original set, only two compounds showed markedly poorer inhibition (cf. Table 1), namely 9d with a particularly large aryl substituent $(19 \mu \mathrm{M})$ and 9q, which has a branched substituent adjacent to the methylene bridge $(29 \mu \mathrm{M})$. In both cases, the additional interactions are likely missing. Furthermore, $\mathbf{9 q}$ is a chiral compound, but commercially available only as racemate, which further hinders a structural explanation for its reduced potency.

Given the small differences in potency by changing the substitution on the secondary amine, it was concluded that the main pharmacophore responsible for efficient inhibition was the 2-(2-aminopyrimidin4-yl)-pyridine-4-carboxylate core itself. This hypothesis was tested using commercially available control compounds, which lacked one or several parts of this scaffold (cf. Supplementary Table 1). These compounds contain different side chain substitutions on the amine compared with the original inhibitors. However, as was established above, these substituents have little influence on the potency of the compounds, which can, thus, still serve as suitable controls.

Compound 10 lacking the carboxylic acid showed a drastic decrease in potency of around tenfold compared with similarly substituted derivatives, which can be attributed to the loss of important interactions with Lys206 and Tyr132. Removal of the carboxylate and masking the hydrogen bond donor capacity of the secondary amine (to Glu190) by methylation (11) led to complete loss of activity. Similarly, moving the substitution pattern of the pyrimidyl-pyridine core away from the 2,2'-binding motif as in the histone deacetylase inhibitor mocetinostat 12 expectedly gave no inhibition as such a compound cannot chelate the central ferrous ion. Loss of flexibility around the methylene group adjacent to the secondary amine by introduction of a sulfonamide linker (13) again led to a drastic increase in the $\mathrm{IC}_{50}$ value.

These in vitro data, thus, confirm the predicted binding mode (Figure 2B) and we reasoned that the main relevant pharmacophore required for inhibition is indeed the pyrimidyl-pyridine core as chelator of the central ferrous ion, stabilized further by an ionic interaction of the carboxylate with the basic amino acid lysine and by a hydrogen bond from the secondary amine to the $\mathrm{H}$-bond accepting glutamate in the active site. The aromatic substituents on the amine serve only to confer additional lipophilic interactions and possibly hydrogen bond interactions of basic substituents with a water-filled subpocket, which can increase potency several fold depending on their nature and orientation. However, the inherent flexibility of the water network and the failure of the docking setup to account for these interactions complicates the deduction of a clearer structure-activity relationship (SAR) for this part of the molecule.

\section{Enlargement of the inhibitor collection}

Encouraged by the information from the initial inhibitor set and the emerging SAR outlined above, we sought to broaden the structural diversity of our inhibitors and investigate further compounds and possibly improve their potency. A second subset of compounds $(9 s-\mathbf{a b})$ was selected from the original virtual screening results and again tested in vitro (cf. Table 1). This set once again yielded potent demethylase inhibitors with $\mathrm{IC}_{50}$ values in the range of 1.6-10.2 $\mu \mathrm{M}$ and, by and large, confirmed the already established SAR. The most potent derivatives were again those with aromatic basic substituents such as $9 \mathbf{u}(1.6 \mu \mathrm{M})$ and $\mathbf{9 w}$ $(2.0 \mu \mathrm{M})$. The pyridyl derivative $9 \mathbf{v}$ was found to be several times less potent $(7.4 \mu \mathrm{M})$ than its counterparts $9 \mathbf{a}$ and $\mathbf{9 b}$, possibly due to inappropriate orientation or distance of the pyridyl nitrogen atom. Aliphatic basic side chains as in $9 \mathbf{a b}$ were not well tolerated $(9.5 \mu \mathrm{M})$.

Most of the substituents in the compounds in the inhibitor sets so far were relatively polar and this, 
together with the carboxylate function, resulted in compounds with very low calculated $\log \mathrm{P}$ values (data not shown). We were, therefore, concerned about issues with cell permeability once the inhibitors were to be used in cell culture experiments. Therefore, we selected a third subset of inhibitors with more lipophilic side chains (9ad-al). The benzyl derivative 9ac was synthesized by us as it was not commercially available (see 'Chemistry' section below).

These compounds were again subjected to in vitro testing in the LANCE assay and the results are summarized in Table 1. All compounds were potent inhibitors of JMJD2A with $\mathrm{IC}_{50}$ values in the range of $0.37-4.1$ $\mu \mathrm{M}$. This set, therefore, showed an improved potency of at least twofold compared with those investigated before. Of particular note are compounds 9ag and 9aj, which are the most potent derivatives in this set with submicromolar $\mathrm{IC}_{50}$ values of $0.37 \mu \mathrm{M}$ and $0.45 \mu \mathrm{M}$, respectively. They also contain aromatic moieties, which comprise a hydrogen bond or dipolar interaction acceptor (chromane in $\mathbf{9 a g}$ and methylsulfanyl in 9aj), respectively. The importance of another $\mathrm{H}$-bond acceptor in this position was already demonstrated with the basic residues in $\mathbf{9 a}, \mathbf{9 j}, \mathbf{9} \mathbf{1}$ and $\mathbf{9 u}$ as discussed above. Intriguingly, the change from the pyridyl residue in $9 \mathbf{a}$ and $9 \mathbf{b}$ to the benzyl residue in $9 \mathbf{a c}$ led to no drastic change in potency ( $2.7 \mu \mathrm{M}$ for 9ac), although the polar interaction with the water-filled subpocket is no longer possible. However, this modification increased $c \log \mathrm{P}$ by more than one unit, which was a promising improvement in physicochemical properties (see below).

Taking together the structural knowledge derived from the previous inhibitor sets, a final subset of compounds was selected from the original virtual screening collection (9am-ar, cf. Table 1). This set contained compounds of remarkable potency with $\mathrm{IC}_{50}$ values at or below $1 \mu \mathrm{M}$, due to their additional polar acceptor moiety such as the bridged catechols in 9an $(0.92 \mu \mathrm{M})$ and 9 ar $(1.3 \mu \mathrm{M})$. Notably, control compounds, in which the cyclic ether motif is reversed, such as 9ap and 9 aq are significantly less potent in comparison. However, these are again chiral compounds, where the individual effect of the two enantiomers could not be assessed. This underlines the importance of the correct orientation of the hydrogen bond acceptor in order to obtain additional interactions with water molecules in the active site pocket, similar to the original observation for lead compounds $\mathbf{9 a}$ and $\mathbf{9 b}$.

\section{Synthesis of methyl ester prodrugs}

In order to obtain compounds suitable for cell culture testing, we reasoned that it would be beneficial to synthesize the corresponding methyl esters 20 of the origi- nal lead structure 9 (cf. Figure 3). By eliminating the negative charge on the carboxylic acid, we hoped to generate compounds with improved cell permeability. These compounds would then be cleaved intracellularly by unspecific esterases to release the carboxylate compounds of structure $\mathbf{9}$ within the cells. The use of methyl esters as prodrugs masking carboxylic acids is well documented in the literature [61]. The establishment of a synthetic platform for these compounds further allowed us to generate derivatives with different substituents that were not commercially available such as the benzyl derivative 9ac.

The general synthetic route is outlined in Figure 3A. The key step is the formation of the pyrimidine heterocycle by condensation of the corresponding guanidines 16 with enaminone 19. A similar reaction was previously reported in the literature such as in the synthesis of mocetinostat 12 (cf. Supplementary Table 1) [62,63]. It allowed us to generate derivatives of the lead structure $\mathbf{9}$ or $\mathbf{2 0}$ in a highly modular approach by simply exchanging the required guanidine all the while using the same pyridylenaminone 19.

The required guanidines $\mathbf{1 6}$ could be synthesized from the corresponding commercially available primary amines $\mathbf{1 4}$ or their hydrochloride salts using pyrazolecarboxamidine $\mathbf{1 5}$ as a well-established guanidinylation reagent [64] in good to excellent yields. The guanidines could be crystallized yielding products $\mathbf{1 6}$ in sufficient purity for the coupling steps.

Pyridylenaminone 19 was built up in two steps from commercial methyl isonicotinate $\mathbf{1 7}$, which was acetylated in a radical iron(II)-catalyzed Minisci-type reaction following a literature procedure $[65,66]$. Acetyl derivative $\mathbf{1 8}$ could then easily be transformed to enaminone 19 with dimethylformamide-dimethylacetal in an aldol condensation reaction under microwave conditions, giving intermediate 19 in good yields [67].

The coupling of enaminone 19 with the corresponding guanidines $\mathbf{1 6}$ was performed analogous to a literature procedure [63] in refluxing iso-propanol under addition of molecular sieves to capture the reaction byproduct dimethylamine. Yields for this coupling reaction ranged from 10 to $42 \%$, mostly due to the troublesome reaction work-up and intense purification in order to reach the desired purity for testing of these compounds, which often involved several chromatographic steps. Furthermore, by refluxing the reaction mixture in iso-propanol, a substantial amount of the iso-propyl esters of $\mathbf{9}$ was sometimes formed, which then needed to be transesterified into the desired methyl esters 20. Methanol as solvent would not reach a high enough reflux temperature required for this reaction. 
(A)
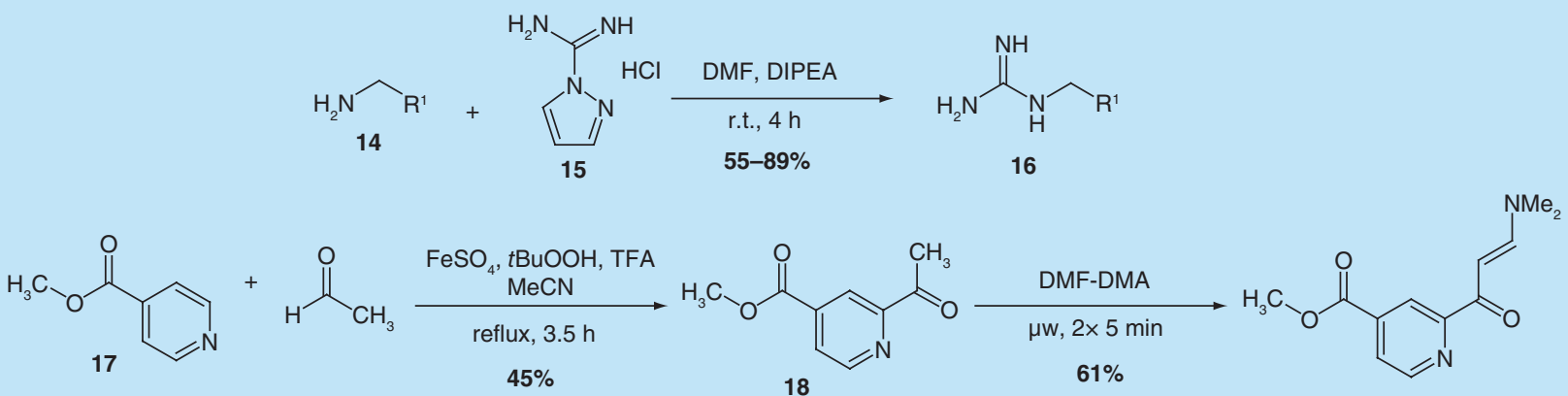

18

19<smiles>CCNc1nccc(-c2cc(C(=O)O)ccn2)n1</smiles>
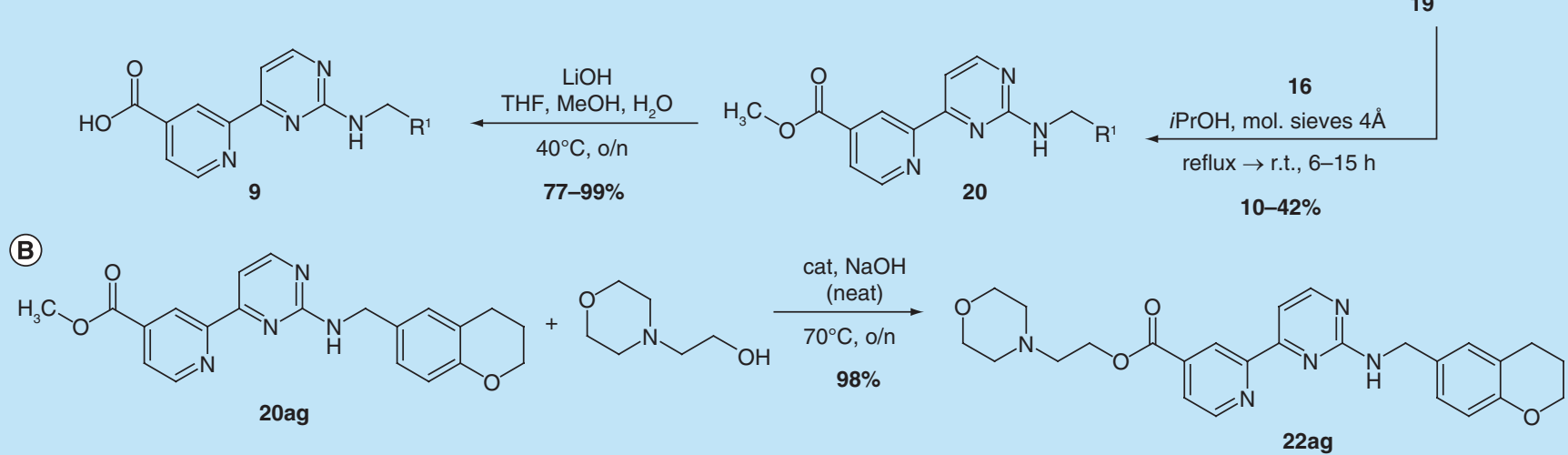

Figure 3. Synthesis of analogs and prodrugs of lead structure 9. (A) Synthesis scheme for synthesis of compounds of the general lead structure 9 and their methyl ester prodrugs 20. (B) Synthesis route for $N$-morpholinoethyl ester 22ag of the most potent inhibitor. Full experimental details can be found in the Supplementary Information.

The low yields are certainly dissatisfying, in particular at the key merging step of a modular synthesis, and leave room for improvement. The focus of this study, however, was to prepare novel compounds in high enough purity for testing rather than optimizing reaction conditions toward high yields. The literature yield for this reaction using similar starting materials, however, was only $52 \%$ as well [63].

In the case of novel compounds with substitutions that were not commercially available, the carboxylic acids 9 could also be prepared from the methyl esters 20 using a standard saponification approach with aqueous lithium hydroxide. The acids could be precipitated in good to excellent yields and did not require further purification.

Expectedly, the methyl esters $\mathbf{2 0}$ all showed markedly reduced potency by at least fivefold in the in vitro assay as compared with their corresponding carboxylates 9 (cf. Supplementary Table $1 \&$ Table 1 ).

This modular synthesis also allowed us to prepare derivatives of the original lead structure that were lacking the carboxylate moiety altogether. For this, the sequence was started using commercial 2-acetylpyridine, which can also be transformed into the enaminone and then coupled with the corresponding guanidines. These compounds (21b and 21ac, cf.
Supplementary Table 1), however, all exhibited dramatically reduced potency in vitro as expected and were not investigated further.

In addition, a prodrug could be synthesized using an $N$-morpholinoethyl ester that is expected to be better soluble in aqueous media than are the methyl esters. As depicted in Figure 3B, the methyl ester 20ag was stirred in an excess of $N$-morpholinoethanol and transesterified by base catalysis. Recovery of the product 22ag by extraction yielded the $N$-morpholinoethyl ester in excellent yield.

\section{Cellular activity of inhibitors}

In order to assess the effect of JMJD2A inhibition by our lead compounds on cell proliferation, we employed a standard colorimetric MTS growth inhibition assay as described in the experimental section. We used KYSE150 esophageal carcinoma cells [47] since they had previously been shown to contain particularly elevated levels of the very closely related $\mathrm{H} 3 \mathrm{~K} 9 \mathrm{me}_{3}$ demethylase JMJD2C (KDM4C) [68], which is likely also inhibited by our compounds, and to be sensitive to JMJD2A (KDM4A) inhibition [69]. The results for selected compounds are summarized in Figure 4. Cell proliferation data in percent are relative to control cells treated with the same amount of DMSO, but not with a compound. 
Despite its remarkable in vitro potency $\left(\mathrm{IC}_{50}=\right.$ $0.94 \mu \mathrm{M})$, compound $\mathbf{9 b}$ had no significant effect on cell proliferation. We believe this to be due to the very polar nature and the negative charge of the molecule, which hamper cell permeability. Its methyl ester prodrug 20b, however, reduced cell proliferation by $50 \%$ at a concentration of $50 \mu \mathrm{M}$.

In our efforts to optimize the physicochemical properties of these compounds, the (pyridin-4-yl) methyl substituent of compound $\mathbf{9 b}$ was replaced by a benzyl unit, leading to an increase in lipophilicity by $1.5 c \log \mathrm{P}$ units, but no dramatic change in in vitro potency (cf. Table 1). Compound 9ac, however, did show significant reduction of cell proliferation by $44 \%$ at $50 \mu \mathrm{M}$. This is remarkable as the switch to a more lipophilic side chain apparently allowed this compound to permeate cells in spite of the negative charge on the carboxylic acid. Its methyl ester prodrug 20ac was also tested hoping for an additional increase in cell permeability by elimination of the charged carboxylate. Unfortunately, due to the increased lipophilicity, its solubility in aqueous cell culture medium was also limited and it could only be tested at concentrations of up to $10 \mu \mathrm{M}$, where a reduction of cell proliferation of only $20 \%$ was observed.

We have also synthesized the methyl esters of our most potent inhibitors 9ag and 9aj, that is, 20ag and 20aj, respectively. For those, the same problems with solubility were encountered as for $\mathbf{2 0 a c}$ and they could not be tested at a high enough concentration to obtain notable effects (data not shown). Testing of their corresponding free carboxylates 9 ag and 9 aj gave no significant reduction in cell proliferation, which may be due to limited cell penetration.

In order to overcome the problem of limited solubility of our inhibitors with lipophilic side chains, we changed our initial prodrug strategy from the methyl ester to the corresponding $N$-morpholinoethyl ester, which can be expected to be much better soluble in aqueous media. The combination of the optimal side chain in 9 ag with this ester led to 22ag, which was indeed soluble at much higher concentrations and could be tested at up to 250

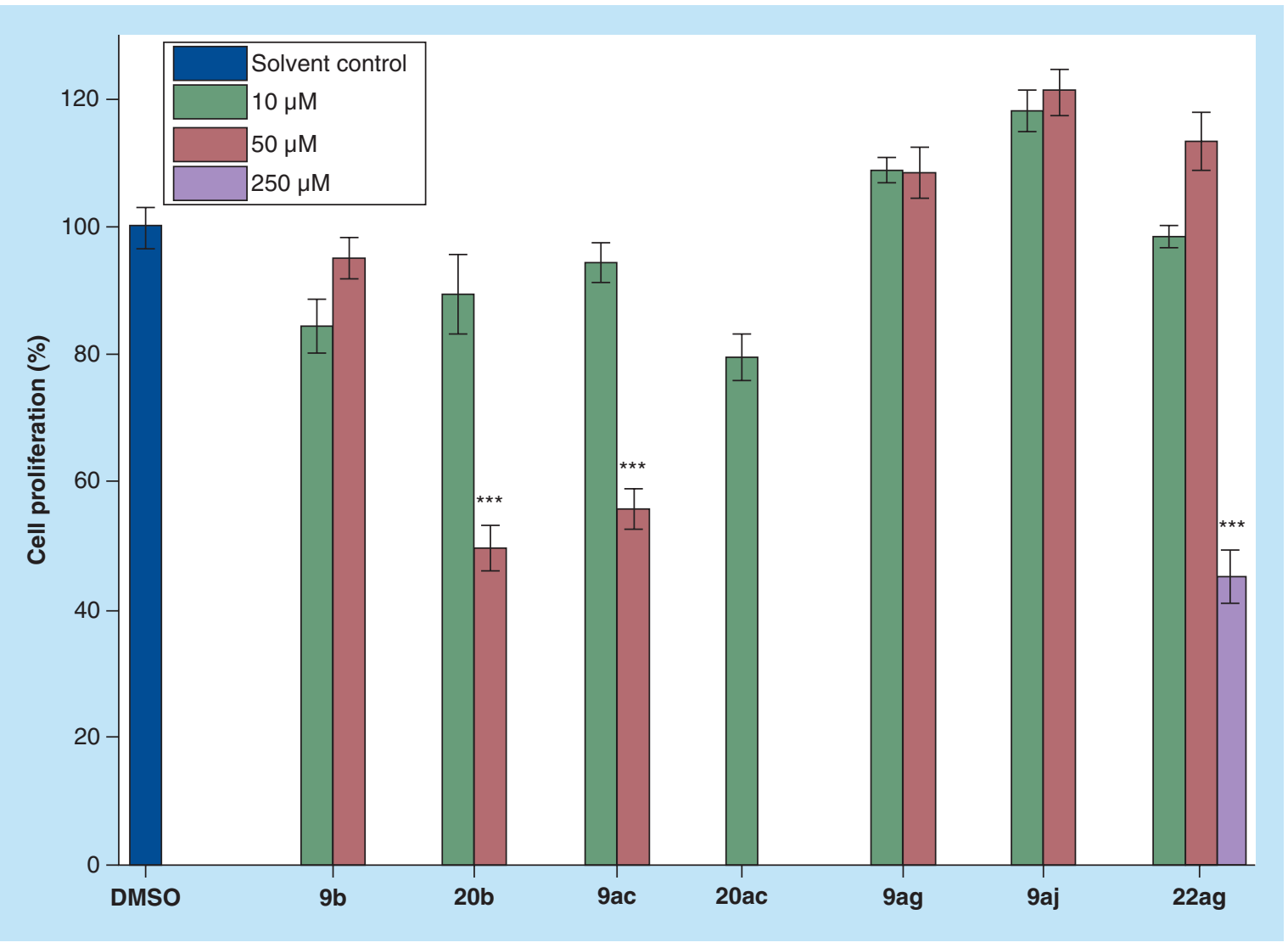

Figure 4. Effect of JMJD2A inhibitors on proliferation of KYSE-150 cells. Compounds with high polarity such as $9 \mathrm{~b}$ show no effect, presumably due to limited cell penetration. Its methyl ester prodrug $20 \mathrm{~b}$ and the more lipophilic benzyl derivative 9ac, however, show significant reduction in cell proliferation. Its ester prodrug 20ac has limited solubility. $\mathrm{N}$-Morpholinoethyl ester $22 \mathrm{ag}$ has no issues with solubility at concentrations of up to $250 \mu \mathrm{M}$ and gives the same reduction in cell proliferation as $20 \mathrm{~b}$ and 9 ac. Values shown are mean \pm SEM of at least 5 wells per inhibitor concentration.

$* * *$ Significant reduction compared with DMSO control $(p<0.0001)$. 
$\mu \mathrm{M}$. As expected, cell proliferation was significantly reduced by $55 \%$ at this concentration. Unfortunately, we saw no notable effect at a lower concentration of $50 \mu \mathrm{M}$. The reason for this may be that the $N$-morpholinoethyl ester is cleaved less well by intracellular esterases as is the methyl ester and, therefore, higher concentrations are required to reach the same biological effect.

In summary, we have demonstrated that our JMJD2A demethylase inhibitors can significantly reduce proliferation of particularly sensitive KYSE150 esophageal carcinoma cells. Optimization of their physicochemical properties in a quite narrow space with regard to cell permeability on the one hand and solubility on the other allowed us to generate potent inhibitor prodrugs with cellular activity. To the best of our knowledge, this is the first report of pyridine carboxylate-based inhibitors with cellular activity.

\section{X-ray crystallography}

In order to better understand the mode of binding of our inhibitors to the active site and to compare it to the predicted binding from virtual screening and docking, we attempted to obtain a cocrystal $x$-ray structure of the original lead structure $\mathbf{9 a}$ in complex with the catalytic domain of the enzyme. JMJD2A-9a cocrystals could be grown by sitting drop vapor diffusion and the resolved structure is depicted in Figure 5 and additional views are shown in Supplementary Figure 2.

As can be seen from the detailed view of the interactions in Figure 5B, 9a adopts the binding pose predicted from docking (see above). The pyridyl- and pyrimidylnitrogen atoms chelate the central ferrous ion, which is also bound by His276, His188 and Glu190. One molecule of water remains coordinated to the ferrous ion. The essential carboxylate group of $\mathbf{9 a}$ forms an additional ionic interaction with Lys206 and a hydrogen bond with Tyr132. This explains why all ester prodrugs and derivatives lacking the carboxylate group (compounds 20 and 21, cf. Supplementary Table 1) exhibit such drastically reduced potency in vitro. The secondary amino group adjacent to the pyrimidine ring forms another hydrogen bond with Glu190, underlining its relevance for potent binding (compare compound 11).

The terminal aryl substituents are connected to the secondary amine via a methylene bridge, which is important as it adopts a bent conformation that allows for the larger rings to be accommodated in the active site (cf. surface representation, Supplementary Figure 2C). The terminal pyridyl ring protrudes into a larger pocket formed by Tyr175, Val171 and Asp191, without forming any specific interactions. The network of water molecules in this pocket, which is likely disturbed by binding of $9 \mathbf{a}$, has not been resolved in the crystal structure, however. This, again, makes it difficult to derive a better understanding of the SAR in this position. It can be assumed that the most potent derivatives form additional interactions in this pocket.

The obtained cocrystal structure allowed us to compare the binding situation of our inhibitor 9a to JMJD2A with that of previously published inhibitors 2,4-PDCA 2 (PDB: 2vd7) [35] and bipyridyl derivative 5b (PDB: 3pdq) [38] as depicted in Supplementary Figure 3. The pyridine ring can be seen to adopt the same position complexing the ferrous ion in all three cases. The same is true for the carboxylate group in contact with Lys206 and Tyr132. While the ferrous ion is additionally chelated by the second carboxylate group of $\mathbf{2}$ and by the other pyridine ring in $\mathbf{5 b}$, in our case this is achieved by the pyrimidyl nitrogen atom in position 3. Compound $\mathbf{5 b}$ forms another salt bridge through its positively charged terminal ethylenediamine moiety with Asp135. Our compound 9a is the first reported inhibitor to address Glu190 forming an additional interaction through its secondary amine, thereby stabilizing its binding. Furthermore, $\mathbf{9 a}$ is the first example of an inhibitor to protrude all the way to the edge of the catalytic pocket into the water-filled subpocket.

\section{Competitivity of inhibition}

The mode of binding that is suggested by docking and the $\mathrm{x}$-ray structure is further corroborated by enzyme kinetic investigations, which clearly show that inhibition of demethylation by JMJD2A by our inhibitors is competitive to the enzyme's cosubstrate 2-oxoglutarate 1a. Results from inhibition experiments using varying concentrations both of inhibitor $\mathbf{9 a g}$ and $\mathbf{1 a}$ are depicted in Figure 6.

Increasing the concentration of $\mathbf{1 a}$ in the absence of inhibitor gives a standard Michaelis-Menten saturation curve for the enzyme's cosubstrate with a $K_{\mathrm{M}}$ value of 1.1 $\mu \mathrm{M}$ for 1a. In the presence of increasing concentrations of inhibitor 9ag, the curve shifts to the right, that is, to higher apparent $K_{\mathrm{M}}$ values for binding of the cosubstrate. However, the maximum velocity of the enzyme remains virtually unchanged within a margin of error. Taking these observations together shows that inhibition is competitive with regard to $1 \mathrm{a}$. The apparent $K_{\mathrm{M}}$ values increase linearly with increasing concentrations of $9 \mathrm{ag}$ and this allows for the calculation of the inhibition constant $K_{\mathrm{i}}$, which is as low as $186 \mathrm{nM}$ for 9 ag.

The observation of competitive inhibition is also true for the original lead compounds $\mathbf{9 a}$ and $\mathbf{9 b}$ (cf. Supplementary Figure 4), for which $K_{\mathrm{i}}$ values of $1.80 \mu \mathrm{M}$ and $579 \mathrm{nM}$ were obtained, respectively.

\section{Selectivity screening}

Finally we set out to investigate the selectivity of our inhibitors toward other histone demethylases of the JmjC 


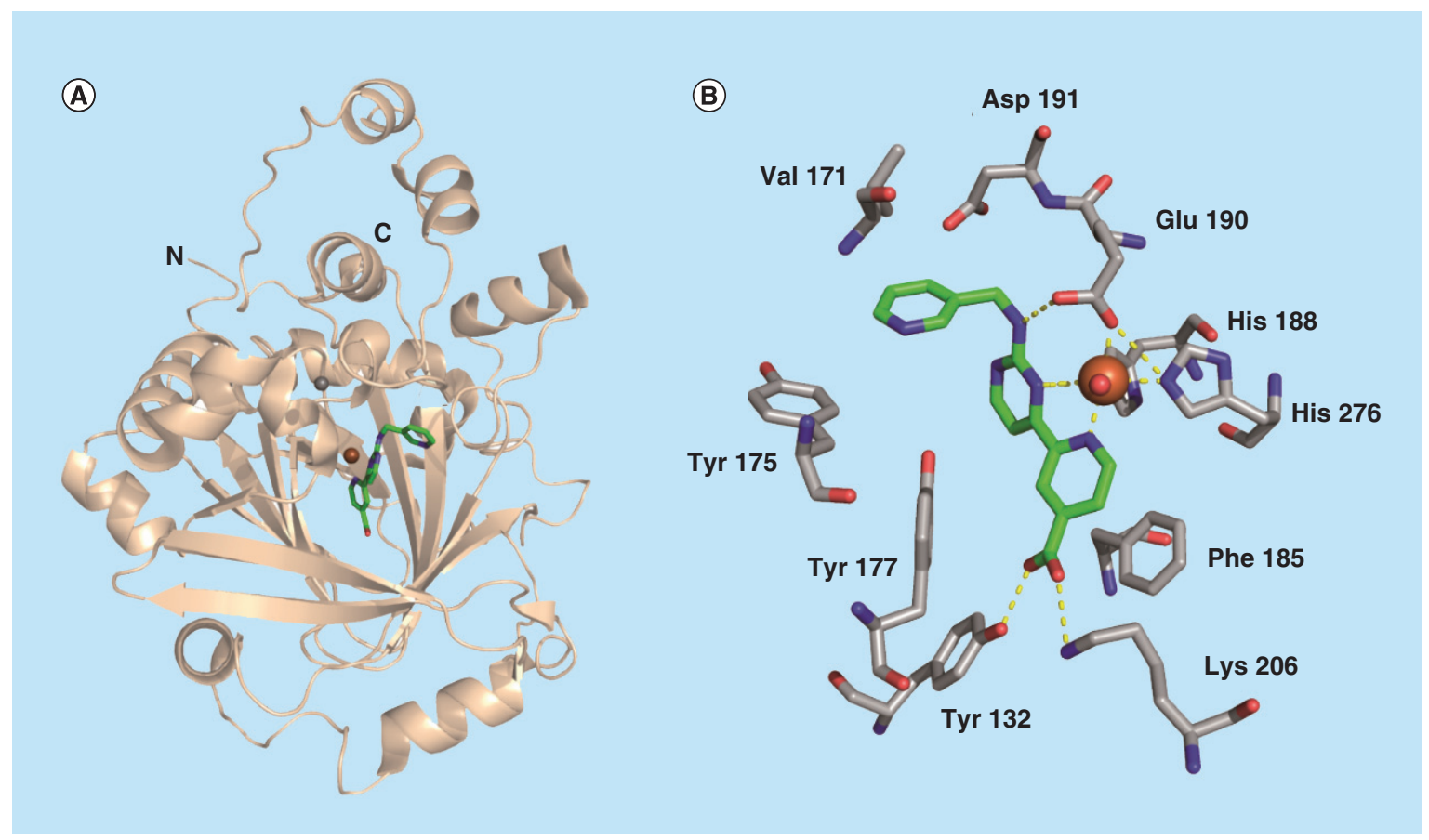

Figure 5. Crystal structure of JMJD2A in complex with 9a. (A) Overall structure of the JumonjiC domain of JMJD2A (1-359) in complex with the ligand shown in green, the Fe atom as a brown sphere and the $\mathrm{Zn}$ atom as a gray sphere. For clarity, only chain A of the molecule is shown. The $\mathrm{N}$ - and C-terminus are labeled. (B) Binding site of the ligand (carbon atoms in green) showing the neighboring residues (some are omitted for clarity), the Fe atom (brown sphere) and coordinated water molecule (red sphere). Hydrogen bonding interactions are shown as yellow dashed lines. Oxygen atoms are shown in red, nitrogen atoms are shown in blue.

family. For this purpose, the LANCEUltra assay was adapted to work with commercially available demethylases JARID1A (KDM5A) and JMJD3 (KDM6B) and their corresponding $\mathrm{H} 3 \mathrm{~K} 4 \mathrm{me}_{3}$ and $\mathrm{H} 3 \mathrm{~K} 27 \mathrm{me}_{3}$ peptide substrates, respectively. Enzyme reaction conditions were optimized and the appropriate LANCE antibodies against the products $\mathrm{H} 3 \mathrm{~K} 4 \mathrm{me}_{2 / 1}$ and $\mathrm{H} 3 \mathrm{~K} 27 \mathrm{me}_{2}$ were used (see the 'Materials \& methods' section). Antibody specificity was checked to verify that they only bind the corresponding product, but not the substrate peptides (data not shown).

We chose JARID1A as a representative of the KDM5 subfamily and JMJD3 of the KDM6 subfamily because of their reported involvement in oncogenesis $[18,19,34]$. Furthermore, the case of GSK-J1 7 as a KDM6 family-selective inhibitor [41] has shown that the development of selective JmjC demethylase inhibitors is, in principle, feasible.

The $\mathrm{IC}_{50}$ values of our inhibitors determined in the various different histone demethylase in vitro assays can be used as an approximate measure of selectivity and are summarized in Table 2 along with those of KDM6-selective inhibitor GSK-J1 7, our recently reported inhibitor $\mathbf{8}$ and 2,4-PDCA 2, which had been reported to be a rather unselective inhibitor, as controls.

While lead compounds $\mathbf{9 a}$ and $\mathbf{9 b}$ are nearly equally potent inhibitors of JMJD2A and JARID1A, they are remarkably less potent on JMJD3 with a difference of nearly 40 -fold in the case of $\mathbf{9 b}$, likely due to differences in size and geometry of the active sites of these enzymes and the location of conserved water molecules. Control compound GSK-J1 7 was most potent on JMJD3 and showed only little inhibition on JMJD2A as reported [41]. However, notable inhibition was also observed on JARID1A, which coincides with reports that provide new data on GSK-J1's selectivity for the KDM6 family [42]. The fragment-like inhibitor 8 shows highest potency on KDM4A with a fourfold difference on KDM5A and a dramatic 41-fold difference on KDM6B. This is remarkable given the small size and low molecular complexity of $\mathbf{8}$ [44]. 2,4-PDCA 2 had the greatest inhibitory effect on JMJD2A, with notably reduced efficacy on JARID1A and above all JMJD3.

Compounds $\mathbf{2 1 b}$ and $\mathbf{2 0 b}$, the derivatives of $\mathbf{9 b}$, which are missing the essential carboxylate moiety or have it masked as a methyl ester, respectively, show much reduced potency on JMJD2A and JARID1A as expected. In the case of JMJD3, there is virtually no inhibitory effect measurable.

The selectivity profile of compounds $\mathbf{9 a}$ and $\mathbf{9 b}$ with regard to the three investigated demethylases is, therefore, remarkable and reinforces the notion that the development of inhibitors with at least subfamily selectivity for KDM4 and KDM5 over KDM6 is possible. 
(A)

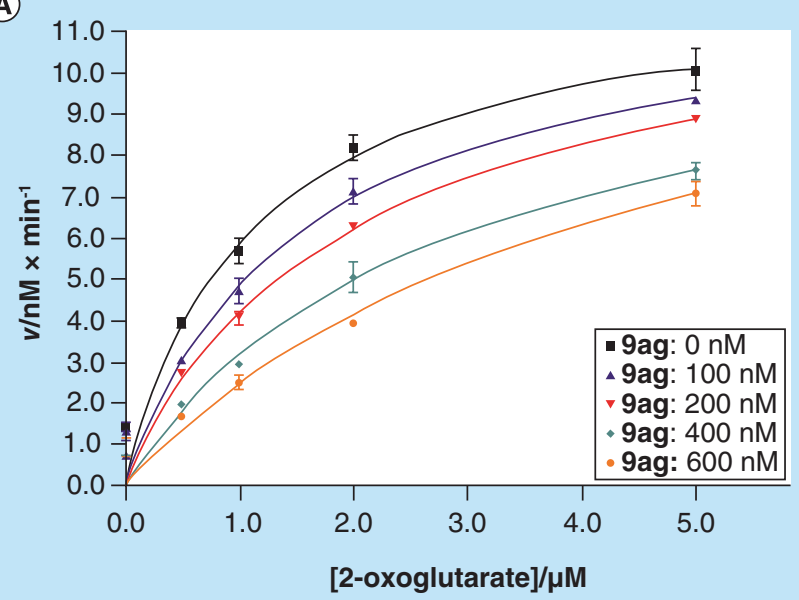

(B)

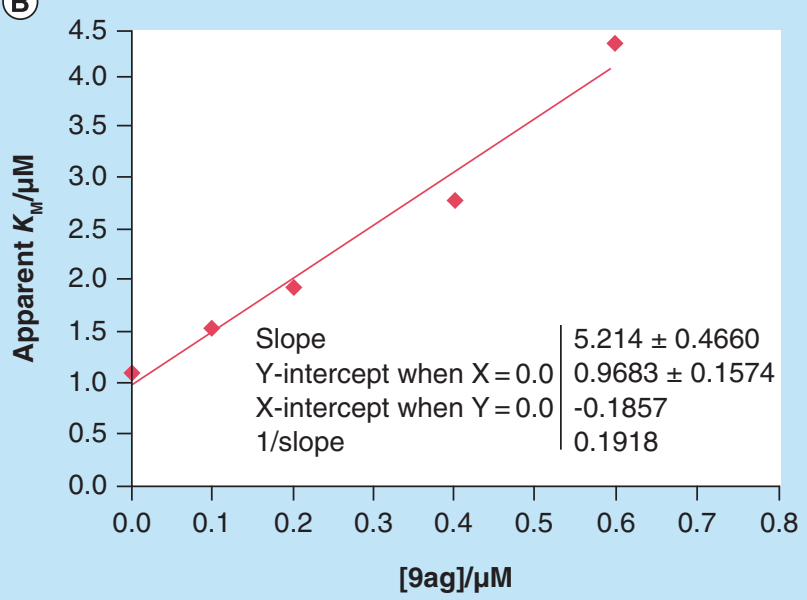

(C)

\begin{tabular}{|c|c|c|c|c|c|}
\hline$[9 \mathrm{ag}] / \mathrm{nM}$ & 0 & 100 & 200 & 400 & 600 \\
\hline$v_{\max } / \mathrm{nM} \times \mathrm{min}^{-1}$ & 12.4 & 12.3 & 12.3 & 11.9 & 13.1 \\
\hline$K_{\mathrm{M}}$ app $/ \mu \mathrm{M}$ & 1.10 & 1.53 & 1.91 & 2.77 & 4.31 \\
\hline
\end{tabular}

Figure 6. Inhibition of JMJD2A by 9ag is competitive to cosubstrate 2-oxoglutarate 1a. (A \& C) As can be seen from the kinetic parameters, maximum velocity of the enzymatic reaction is virtually unaffected by increasing concentrations of inhibitor. (B) However, the apparent Michaelis-Menten constant for 2-oxoglutarate increases as a linear function of inhibitor concentration. The inhibition constant $K_{\mathrm{i}}$ is determined to be $186 \mathrm{nM}$.

However, given the similarity in $\mathrm{IC}_{50}$ values on JMJD2A and JARID1A, the observed cellular effects may of course also be due to a mixed inhibition of both or other demethylases.

\section{Conclusion}

JmjC histone demethylases have been recognized as vital players in the development of a number of tumor dis- eases. Here, we have used virtual screening of a database of commercially available compounds to identify a novel scaffold for inhibitors of these enzymes with remarkable in vitro potency. Through rational selection processes, we were able to obtain optimized compounds culminating in the discovery of $9 \mathbf{a g}$ with a $K_{\mathrm{i}}$ of $186 \mathrm{nM}$, which makes this one of the most potent inhibitors of JMJD2A reported to date. A synthetic strategy was established to

\section{Table 2. Selectivity data for selected compounds against various JumonjiC histone demethylases.}

\begin{tabular}{|c|c|c|c|}
\hline Compound & $\begin{array}{l}\text { JMJD2A (KDM4A) } 60 \mathrm{nM} \text { enzyme, } \\
400 \mathrm{nM} \text { peptide substrate, } 45 \mathrm{~min} \\
\text { reaction @ r.t. }\end{array}$ & $\begin{array}{l}\text { JARID1A (KDM5A) } 25 \mathrm{nM} \text { enzyme, } \\
100 \mathrm{nM} \text { peptide substrate, } 45 \mathrm{~min} \\
\text { reaction @ r.t. }\end{array}$ & $\begin{array}{l}\text { JMJD3 (KDM6B) } 50 \mathrm{nM} \text { enzyme, } \\
400 \mathrm{nM} \text { peptide substrate, } 120 \mathrm{~min} \\
\text { reaction @ r.t. }\end{array}$ \\
\hline 2,4-PDCA 2 & $0.0337 \pm 0.0070 \mu \mathrm{M}$ & $0.100 \pm 0.028 \mu \mathrm{M}$ & $36.0 \pm 4.7 \mu \mathrm{M}$ \\
\hline GSK-J1 7 & $54.4 \pm 1.6 \mu \mathrm{M}$ & $0.418 \pm 0.153 \mu \mathrm{M}$ & $0.128 \pm 0.018 \mu \mathrm{M}$ \\
\hline 8 & $2.38 \pm 0.37 \mu \mathrm{M}$ & $10.4 \pm 1.8 \mu \mathrm{M}$ & $98.0 \pm 7.2 \mu \mathrm{M}$ \\
\hline $9 a$ & $3.98 \pm 1.26 \mu \mathrm{M}$ & $1.04 \pm 0.22 \mu \mathrm{M}$ & $16.2 \pm 1.7 \mu \mathrm{M}$ \\
\hline $9 b$ & $0.941 \pm 0.052 \mu \mathrm{M}$ & $0.442 \pm 0.067 \mu \mathrm{M}$ & $36.5 \pm 3.6 \mu \mathrm{M}$ \\
\hline $20 \mathrm{~b}$ & $163 \pm 11 \mu \mathrm{M}$ & $112 \pm 35 \mu \mathrm{M}$ & $387 \pm 19 \mu \mathrm{M}$ \\
\hline $21 b$ & $67.7 \pm 1.5 \mu \mathrm{M}$ & $165 \pm 17 \mu \mathrm{M}$ & $\sim 500 \mu \mathrm{M}$ \\
\hline
\end{tabular}


derivatize these compounds into cell-permeable prodrugs with antiproliferative activity against an esophageal cancer cell line. The mode of binding of these highly potent inhibitors was elucidated by $\mathrm{x}$-ray crystallography and enzyme kinetic experiments. These compounds can, therefore, serve as valuable lead structures for therapeutic candidates and biological tool compounds.

\section{Future perspective}

For a number of oncology indications, there is an unmet clinical need for potent and selective therapeutic compounds. It is understood that epigenetic mechanisms play a vital role in the manifestation and progression of these diseases $[5,8]$. However, there are only few potent inhibitors of epigenetic enzymes available to date. This study contributes to the field by providing a novel lead structure scaffold and a prodrug strategy for highly potent JmjC histone demethylase inhibitors with cellular activity. Future research will focus on the optimization of their physicochemical properties and the functional characterization of their biological effects. Meanwhile, the impact of selective histone demethylase inhibition will need to be investigated by showing direct intracellular effects and functional responses, possibly also in animal models of the disease state.

Supplementary data \& methods

To view the supplementary data that accompany this paper please visit the journal website at: www.future-science.com/ doi/full/10.4155/fmc.15.188
The crystal structure of $\mathbf{9 a}$ in complex with JMJD2A has been deposited to the Protein Data Bank (www.PDB.org) under accession code 5anq.

\section{Acknowledgements}

We would like to thank K Schmidtkunz (University of Freiburg) for assistance with cell culture experiments and Dr. X Lucas (University of Freiburg) for help in analyzing physicochemical properties of our lead compounds. We thank S Hesketh (Diamond Light Source) for help with protein production and crystallization. The authors would like to thank the Diamond Light Source for beam time and their staff for assistance with data collection.

\section{Financial \& competing interests disclosure}

This work was funded by the Collaborative Research Center CRC 992 MEDEP 'Medical Epigenetics' (Project A04 to M Jung and Project B01 to R Schüle). R Schüle was further supported by grants from the European Research Council (ERC AdGrant 322844) and the Deutsche Forschungsgemeinschaft (CRC 850, CRC 746, and Schu688/12-1). We thank the COST action CM1406 (Epigenetic Chemical Biology EPICHEMBIO) for support. The OPPF-UK is funded by the Medical Research Council UK (Grant MR/K018779/1). M Roatsch is grateful for support through a doctoral scholarship from the Studienstiftung des deutschen Volkes. The authors have no other relevant affiliations or financial involvement with any organization or entity with a financial interest in or financial conflict with the subject matter or materials discussed in the manuscript apart from those disclosed.

No writing assistance was utilized in the production of this manuscript.

\section{Executive summary}

Virtual screening identified a novel lead structure scaffold for JumonjiC histone demethylase inhibitors

- JumonjiC histone demethylases like JMJD2A are iron(II)- and 2-oxoglutarate-dependent epigenetic erasers, which have been implicated in a variety of tumor diseases.

- By screening the ZINC drug-like database for metal-binding motifs and selection of the retrieved hits by docking to known crystal structures of JMJD2A, a group of 20 potential inhibitors was obtained.

- In vitro testing revealed the 2-(2-aminopyrimidin-4-yl)pyridine-4-carboxylates $9 \mathrm{a}$ and $9 \mathrm{~b}$ to be promising lead structures with remarkable potency. Larger and more diverse sets of compounds were acquired and tested, confirming the predicted binding mode and leading to submicromolar potent demethylase inhibitors like 9ag.

Inhibitor prodrug strategy \& cellular effects

- Establishment of a synthetic platform allowed for the generation of more analogs and the synthesis of methyl ester prodrugs.

- While the acidic inhibitors generally show poor effects on KYSE-150 cell proliferation, their methyl ester prodrugs can potently reduce cell proliferation.

- Optimization of the physicochemical properties is possible, but only in a narrow space between making the compounds cell-permeable, while also retaining their solubility.

Characterization of the mode of inhibition

- X-ray crystallography of 9a in complex with the catalytic domain of JMJD2A revealed the mode of binding of our inhibitors, which confirms the predicted binding from docking.

- Enzyme kinetic experiments confirm our inhibitors to be cosubstrate competitors.

- A remarkable dual selectivity for JMJD2A and JARID1A over JMJD3 was demonstrated. 


\section{Open access}

This article is distributed under the terms of the Creative Commons Attribution License 4.0 which permits any use, distribu- tion, and reproduction in any medium, provided the original author(s) and the source are credited. To view a copy of the license, visit http://creativecommons.org/licenses/by/4.0/

\section{References}

Papers of special note have been highlighted as:

- of interest; $\bullet$ • of considerable interest

1 Kouzarides T. Chromatin modifications and their function. Cell 128(4), 693-705 (2007).

2 Chi P, Allis CD, Wang GG. Covalent histone modifications - miswritten, misinterpreted and mis-erased in human cancers. Nat. Rev. Cancer 10 (7), 457-469 (2010).

3 Butler JS, Koutelou E, Schibler AC, Dent SYR. Histonemodifying enzymes: regulators of developmental decisions and drivers of human disease. Epigenomics 4(2), 163-177 (2012).

4 Berger SL. The complex language of chromatin regulation during transcription. Nature 447(7143), 407-412 (2007).

5 Arrowsmith CH, Bountra C, Fish PV, Lee K, Schapira M. Epigenetic protein families: a new frontier for drug discovery. Nat. Rev. Drug Discov. 11(5), 384-400 (2012).

6 Martin C, Zhang Y. The diverse functions of histone lysine methylation. Nat. Rev. Mol. Cell Biol. 6(11), 838-849 (2005).

7 Zhang Y, Reinberg D. Transcription regulation by histone methylation: interplay between different covalent modifications of the core histone tails. Genes Dev. 15(18), 2343-2360 (2001).

8 Huston A, Arrowsmith CH, Knapp S, Schapira M. Probing the epigenome. Nat. Chem. Biol. 11(8), 542-545 (2015).

- Seminal commentary detailing the importance of finding epigenetic inhibitors for therapy and as biological tool compounds.

9 Spannhoff A, Hauser A-T, Heinke R, Sippl W, Jung M. The emerging therapeutic potential of histone methyltransferase and demethylase inhibitors. ChemMedChem 4(10), 1568-1582 (2009).

10 Rice JC, Allis CD. Histone methylation versus histone acetylation: new insights into epigenetic regulation. Curr. Opin. Cell Biol. 13(3), 263-273 (2001).

11 Shi Y, Lan F, Matson C et al. Histone demethylation mediated by the nuclear amine oxidase homolog LSD1. Cell 119(7), 941-953 (2004).

12 Metzger E, Wissmann M, Yin N et al. LSD1 demethylates repressive histone marks to promote androgen-receptordependent transcription. Nature 437(7057), 436-439 (2005).

13 Tsukada Y, Fang J, Erdjument-Bromage $\mathrm{H}$ et al. Histone demethylation by a family of JmjC domain-containing proteins. Nature 439 (7078), 811-816 (2006).

-. First report of histone demethylation by a member of the JumonjiC family.

14 Whetstine JR, Nottke A, Lan F et al. Reversal of histone lysine trimethylation by the JMJD2 family of histone demethylases. Cell 125(3), 467-481 (2006).
15 Klose RJ, Kallin EM, Zhang Y. JmjC-domain-containing proteins and histone demethylation. Nat. Rev. Genet. 7(9), 715-727 (2006).

16 Johansson C, Tumber A, Che K et al. The roles of Jumonjitype oxygenases in human disease. Epigenomics 6(1), 89-120 (2014).

- The authors extensively review the roles of JumonjiC demethylases in human disease.

17 Hoffmann I, Roatsch M, Schmitt ML et al. The role of histone demethylases in cancer therapy. Mol. Oncol. 6(6), 683-703 (2012).

18 Rasmussen PB, Staller P. The KDM5 family of histone demethylases as targets in oncology drug discovery. Epigenomics 6(3), 277-286 (2014).

19 Burchfield JS, Li Q, Wang HY, Wang R-F. JMJD3 as an epigenetic regulator in development and disease. Int. J. Biochem. Cell Biol. 67, 148-157 (2015).

20 Højfeldt JW, Agger K, Helin K. Histone lysine demethylases as targets for anticancer therapy. Nat. Rev. Drug Discov. 12(12), 917-930 (2013).

21 Guerra-Calderas L, González-Barrios R, Herrera LA, Cantú de León D, Soto-Reyes E. The role of the histone demethylase KDM4A in cancer. Cancer Genet. 208(5), 215-224 (2015).

- The authors summarize the diverse roles of JMJD2A in oncology.

$22 \mathrm{Ng}$ SS, Kavanagh KL, McDonough MA et al. Crystal structures of histone demethylase JMJD2A reveal basis for substrate specificity. Nature 448(7149), 87-91 (2007).

23 Shin S, Janknecht R. Activation of androgen receptor by histone demethylases JMJD2A and JMJD2D. Biochem. Biophys. Res. Commun. 359(3), 742-746 (2007).

24 Berry WL, Shin S, Lightfoot SA, Janknecht R. Oncogenic features of the JMJD2A histone demethylase in breast cancer. Int. J. Oncol. 41(5), 1701-1706 (2012).

25 Patani N, Jiang WG, Newbold RF, Mokbel K. Histonemodifier gene expression profiles are associated with pathological and clinical outcomes in human breast cancer. Anticancer Res. 31(12), 4115-4125 (2011).

26 Kim T-D, Shin S, Berry WL, Oh S, Janknecht R. The JMJD2A demethylase regulates apoptosis and proliferation in colon cancer cells. J. Cell. Biochem. 113(4), 1368-1376 (2012).

27 Mallette FA, Richard S. JMJD2A promotes cellular transformation by blocking cellular senescence through transcriptional repression of the tumor suppressor CHD5. Cell Rep. 2(5), 1233-1243 (2012).

28 Kogure M, Takawa M, Cho H-S et al. Deregulation of the histone demethylase JMJD2A is involved in human carcinogenesis through regulation of the $\mathrm{G}_{1} / \mathrm{S}$ transition. Cancer Lett. 336(1), 76-84 (2013). 
29 Kauffman EC, Robinson BD, Downes MJ et al. Role of androgen receptor and associated lysine-demethylase coregulators, LSD1 and JMJD2A, in localized and advanced human bladder cancer. Mol. Carcinog. 50 (12), 931-944 (2011).

30 Lohse B, Kristensen JL, Kristensen LH et al. Inhibitors of histone demethylases. Bioorg. Med. Chem. 19(12), 3625-3636 (2011).

31 Suzuki T, Miyata N. Lysine demethylases inhibitors. J. Med. Chem. 54(24), 8236-8250 (2011).

32 Thinnes CC, England KS, Kawamura A, Chowdhury R, Schofield CJ, Hopkinson RJ. Targeting histone lysine demethylases - progress, challenges, and the future. Biochim. Biophys. Acta 1839(12), 1416-1432 (2014).

33 Hauser A-T, Roatsch M, Schulz-Fincke J, Robaa D, Sippl W, Jung M. Discovery of histone demethylase inhibitors. In: Epigenetic Technological Applications. Zheng YG (Ed.). Academic Press, Amsterdam, The Netherlands, 397-424 (2015).

34 McGrath J, Trojer P. Targeting histone lysine methylation in cancer. Pharmacol. Ther. 150, 1-22 (2015).

35 Rose NR, Ng SS, Mecinović J et al. Inhibitor scaffolds for 2-oxoglutarate-dependent histone lysine demethylases. J. Med. Chem. 51(22), 7053-7056 (2008).

- First report of a diverse set of histone demethylase inhibitor lead structures derived from cosubstrate analogs and metal chelators.

36 Al-Qahtani K, Jabeen B, Sekirnik R et al. The broad spectrum 2-oxoglutarate oxygenase inhibitor $N$ oxalylglycine is present in rhubarb and spinach leaves. Phytochemistry 117, 456-461 (2015).

37 Hamada S, Suzuki T, Mino K et al. Design, synthesis, enzyme-inhibitory activity, and effect on human cancer cells of a novel series of Jumonji domain-containing protein 2 histone demethylase inhibitors. J. Med. Chem. 53(15), 5629-5638 (2010).

38 Chang K-H, King ONF, Tumber A et al. Inhibition of histone demethylases by 4-Carboxy-2,2'-Bipyridyl compounds. ChemMedChem 6(5), 759-764 (2011).

- Optimization and SAR of 2,2'-bipyridyl compounds as JMJD2E inhibitors.

39 King ONF, Li XS, Sakurai M et al. Quantitative highthroughput screening identifies 8 -Hydroxyquinolines as cell-active histone demethylase inhibitors. PLOS ONE 5(11), e15535 (2010).

40 Rotili D, Tomassi S, Conte M et al. Pan-histone demethylase inhibitors simultaneously targeting Jumonji $\mathrm{C}$ and lysine-specific demethylases display high anticancer Activities. J. Med. Chem. 57(1), 42-55 (2014).

41 Kruidenier L, Chung C-W, Cheng Z et al. A selective jumonji H3K27 demethylase inhibitor modulates the proinflammatory macrophage response. Nature 488(7411), 404-408 (2012).

-. The authors report on an outstandingly potent histone demethylase inhibitor with presumed subfamily selectivity.
42 Heinemann B, Nielsen JM, Hudlebusch HR et al. Inhibition of demethylases by GSK-J1/J4. Nature 514(7520), e1-e2 (2014).

43 Kruidenier L, Chung C-W, Cheng Z et al. Inhibition of demethylases by GSK-J1/J4 reply. Nature 514(7520), e2-e2 (2014).

44 Rüger N, Roatsch M, Emmrich T et al. Tetrazolylhydrazides as selective fragment-like inhibitors of the JumonjiC-domain-containing histone demethylase KDM4A. ChemMedChem 10(11), 1875-1883 (2015).

45 Meier R, Pippel M, Brandt F, Sippl W, Baldauf C. PARADOCKS: a framework for molecular docking with population-based metaheuristics. J. Chem. Inf. Model. 50(5), 879-889 (2010).

46 Verdonk ML, Cole JC, Hartshorn MJ, Murray CW, Taylor RD. Improved protein-ligand docking using GOLD. Proteins 52 (4), 609-623 (2003).

47 Shimada Y, Imamura M, Wagata T, Yamaguchi N, Tobe T. Characterization of 21 newly established esophageal cancer cell lines. Cancer 69(2), 277-284 (1992).

48 Bird LE. High throughput construction and small scale expression screening of multi-tag vectors in Escherichia Coli Methods 55(1), 29-37 (2011).

49 Berrow NS, Alderton D, Sainsbury S et al. A versatile ligation-independent cloning method suitable for highthroughput expression screening applications. Nucleic Acids Res. 35(6), e45 (2007).

50 Studier FW. Protein production by auto-induction in high-density shaking cultures. Protein Expr. Purif. 41(1), 207-234 (2005).

51 Nichols CE, Sainsbury S, Ren J et al. The structure of NMB1585, a MarR-family regulator from Neisseria meningitidis. Acta Crystallogr. Sect. F Struct. Biol. Cryst. Commun. 65(3), 204-209 (2009).

52 Walter TS, Diprose JM, Mayo CJ et al. A procedure for setting up high-throughput nanolitre crystallization experiments. Crystallization workflow for initial screening, automated storage, imaging and optimization. Acta Crystallogr. 61(6), 651-657 (2005).

53 Lobley CMC, Aller P, Douangamath A et al. Structure of ribose 5-phosphate isomerase from the probiotic bacterium Lactobacillus salivarius UCC118. Acta Crystallogr. 66(2), 125-132 (2010).

54 Kabsch W. XDS. ActaCrystallogr. Sect. D: Biol. Crystallogr. 66(2), 125-132 (2010).

55 Evans PR, Murshudov GN. How good are my data and what is the resolution? Acta Crystallogr. 69 (7), 1204-1214 (2013).

56 Vagin A, Teplyakov A. MOLREP: an automated program for molecular replacement. J. Appl. Cryst. 30 (6), 1022-1025 (1997).

57 Collaborative Computational Project Number 4. The CCP4 suite: programs for protein crystallography. Acta Crystallogr. 50(5), 760-763 (1994).

58 Emsley P, Lohkamp B, Scott WG, Cowtan K. Features and development of Coot. Acta Crystallogr. 66(4), 486-501 (2010). 
rshudov GN, Vagin AA, Dodson EJ. Refinement of macromolecular structures by the maximum-likelihood method. Acta Crystallogr. 53(3), 240-255 (1997).

Chen VB, Arendall WB III, Headd JJ et al. MolProbity: all-atom structure validation for macromolecular crystallography. Acta Crystallogr. 66(1), 12-21 (2010).

61 Maag H. Prodrugs of carboxylic acids. In: Prodrugs: Challenges and Rewards Part 1. Stella VJ, Borchardt RT, Hageman MJ, Oliyai R, Maag H, Tilley JW (Eds). Springer, NY, USA, 703-729 (2007).

Zhou N, Moradei O, Raeppel S et al. Discovery of $N$-(2Aminophenyl)-4-[(4-pyridin-3-ylpyrimidin-2-ylamino)methyl] benzamide (MGCD0103), an orally active histone deacetylase inhibitor. J. Med. Chem. 51(14), 4072-4075 (2008). Moradei O, Paquin I, Leit S et al. WO2005030704 (2005).

Bernatowicz MS, Wu Y, Matsueda GR. 1H-Pyrazole1-carboxamidine Hydrochloride: an attractive reagent for guanylation of amines and its application to peptide synthesis. J. Org. Chem. 57(8), 2497-2502 (1992).
65 Dehaudt J, Husson J, Guyard L. A more efficient synthesis of 4,4',4"-tricarboxy-2,2':6',2"-terpyridine. Green Chem. 13(12), 3337-3340 (2011).

66 Wadman SH, Kroon JM, Bakker K, Havenith RWA, van Klink GPM, van Koten G. Cyclometalated organoruthenium complexes for application in dye-sensitized solar cells. Organometallics 29(7), 1569-1579 (2010).

67 Al-Zaydi KM, Borik RM. Microwave assisted condensation reactions of 2-Aryl hydrazonopropanals with nucleophilic reagents and dimethyl acetylenedicarboxylate. Molecules 12(8), 2061-2079 (2007).

68 Cloos PAC, Christensen J, Agger K et al. The putative oncogene GASC1 demethylates tri- and dimethylated lysine 9 on histone H3. Nature 442(7100), 307-311 (2006).

69 Luo X, Liu Y, Kubicek S et al. A selective inhibitor and probe of the cellular functions of Jumonji C domain-containing histone demethylases. J. Am. Chem. Soc. 133(24), 9451-9456 (2011). 